\title{
Benign Subglottis Neoplasm
}

National Cancer Institute

\section{Source}

National Cancer Institute. Benign Subglottis Neoplasm. NCI Thesaurus. Code C4427.

A non-metastasizing neoplasm that arises from the subglottis. 